'Departamento de Anatomía Patológica, Facultad de Medicina, Pontificia Universidad Católica de Chile. Santiago, Chile.

2Departamento de Cirugía Digestiva, Facultad de Medicina, Pontificia Universidad Católica de Chile. Santiago, Chile. anterna de Medicina, Pontificia Universidad Católica de Chile. Santiago, Chile

${ }^{b}$ Residente de Cirugía Digestiva, Facultad de Medicina, Pontificia Universidad Católica de Chile. Santiago, Chile.

Trabajo no recibió financiamiento. Los autores declaran no tener conflictos de intereses.

Recibido el 5 de septiembre de 2020, aceptado el 13 de abril de 2021.

Correspondencia a: Dr. Nicolás Quezada Departamento de Cirugía Digestiva

Facultad de Medicina Pontificia Universidad Católica de Chile.

Diagonal Paraguay $362,4^{\circ}$ piso, Oficina 410. Santiago, Chile. nfquezada@gmail.com

\section{Angioma de células litorales del bazo. Un diagnóstico de lesión focal esplénica. Caso clínico}

\author{
MARÍA J. IRARRÁZAVAL ${ }^{\mathrm{a}}$, SERGIO A. RIVEROS ${ }^{\mathrm{b}}$, \\ JOSÉ R. VALBUENA ${ }^{1}$, NICOLÁS F. QUEZADA ${ }^{2}$
}

\section{Littoral cell angioma of the spleen. Report of one case}

Splenic vascular neoplasms are the most common form of spleen tumors. Among them, littoral cell angioma is rare and it is frequently an incidental finding in imaging studies. It has no specific clinical, laboratory or imaging findings. Splenectomy allows definitive diagnosis throughout a histopathological examination. We report a 52-year-old man presenting with asthenia and abdominal distension. Computed tomography with intravenous contrast showed multiple splenic hypodense masses and a prostatic enlargement. Presuming a lymphoma, a laparoscopic splenectomy was performed. Histopathologic examination diagnosed littoral cell angioma. During urological follow-up, a prostate adenocarcinoma was diagnosed.

(Rev Med Chile 2021; 149: 626-629)

Key words: Neoplasms, Vascular Tissue; Spleen; Splenic Neoplasms; Splenectomy.
L as lesiones focales esplénicas llevan a considerar múltiples diagnósticos diferenciales, entre estos, los abscesos y el linfoma son los más frecuentes. Dentro de las neoplasias esplénicas, las vasculares podrían corresponder al tipo de tumor más común ${ }^{1}$. El angioma de células litorales (ACL) es infrecuente y la mayoría de las veces corresponde a un hallazgo incidental en estudios imagenológicos ${ }^{2}$. No existen factores clínicos, de laboratorio o de imágenes que orienten al diagnóstico. Así, la esplenectomía es un elemento crucial para un correcto diagnóstico mediante el análisis de la biopsia.

El objetivo de este trabajo es describir el caso clínico de un paciente con ACL que inicialmente se presentó como lesión focal esplénica sugerente de linfoma. Adicionalmente, se presenta una revisión de la literatura sobre el ACL, con el objetivo de ampliar el conocimiento sobre esta neoplasia vascular benigna.

\section{Caso clínico}

Paciente masculino de 52 años, con antecedentes de uropatía obstructiva baja en estudio, sin otros antecedentes médicos. Presentó un cuadro de astenia y distensión abdominal de 8 meses de evolución, asociado a baja de peso de $18 \mathrm{~kg}$, como consecuencia de tratamiento con fentermina. No presentaba sudoración nocturna ni fiebre. De su examen físico destacaba sobrepeso, con IMC de $29 \mathrm{Kg} / \mathrm{m}^{2}$, sin otros hallazgos significativos. Los exámenes de laboratorio estaban dentro de limites normales (hemograma, pruebas de coagulación, función renal y perfil bioquímico). Se realizó estudio con tomografía computada de tórax, abdomen y pelvis con contraste intravenoso, el que evidenció el bazo de tamaño conservado, con múltiples lesiones nodulares hipodensas de márgenes mal definidos, que no captaban el contraste intravenoso, 



Figura 1. TAC de abdomen con contraste endovenoso, corte axial. Flecha identifica lesiones. A: fase sin contraste. B: fase contrastada endovenosa.

la mayor de $13 \mathrm{~mm}$ de diámetro (Figura 1), y un aumento del tamaño prostático.

Por sospecha de linfoma esplénico, se planteó una esplenectomía laparoscópica, la que se realizó sin incidentes. Dada la necesidad de análisis histológico, la extracción de la pieza se realizó mediante laparotomía de Pfannenstiel en lugar de fragmentar el bazo. Presentó una evolución postoperatoria favorable y es dado de alta al segundo día postoperatorio.

Al examen macroscópico, se describió un bazo de 9 × 7 x $3 \mathrm{~cm}$ y de $138 \mathrm{~g}$. Al corte se observó tejido rojo-violáceo granular y se reconoció un nódulo rosado rojizo, mal delimitado, periférico, de 0,6 $\mathrm{cm}$ de diámetro. Microscópicamente, se identificó tejido esplénico con una lesión constituida por canales vasculares irregulares con eritrocitos en su interior, con proyecciones papilares revestidas por una capa de células histiocitarias, algunas de las cuales se desprendían al lumen (Figuras 2A y 2B). Se complementó con análisis inmunohistoquímico el cual fue positivo en células neoplásicas para CD31 y CD68, lo cual es compatible con ACL (Figuras 2C y 2D).

En el seguimiento diferido por Urología, en contexto del estudio de su hiperplasia prostática, una biopsia de próstata concluyó adenocarcinoma de próstata. Continúa tratamiento por el equipo de Urología.

\section{Discusión}

Las neoplasias vasculares son el tipo de tumor esplénico más frecuente ${ }^{1}$. El diagnóstico diferencial de estas lesiones incluye al hemangioma, hamartoma, linfangioma, hematopoyesis extramedular, transformación angiomatoide nodular esclerosante y, con una frecuencia menor, el ACL.

El ACL fue descrito por primera vez en 1991 por Falk et al. ${ }^{3}$ en una serie de 17 pacientes sometidos a esplenectomía y, a la fecha, se han descrito alrededor de 150 casos. Dada su baja frecuencia, no es posible determinar una edad característica de presentación ni predominio por género ${ }^{4}$. Aproximadamente, $50 \%$ de los casos son diagnosticados como hallazgo incidental, siendo frecuente su diagnóstico posterior a la esplenectomía por sospecha de otras enfermedades. Las manifestaciones clínicas atribuibles a ACL son inespecíficas y corresponden a dolor abdominal, síntomas constitucionales, anemia, trombocitopenia o esplenomegalia, entre otras.

En el estudio de imágenes, la tomografía axial computada (TAC) con contraste intravenoso demuestra con frecuencia un bazo aumentado de tamaño con múltiples imágenes nodulares hipodensas de diferentes tamaños ${ }^{5,6}$. Sin embargo, no existe un patrón específico en cuanto a las características imagenológicas, pudiendo 


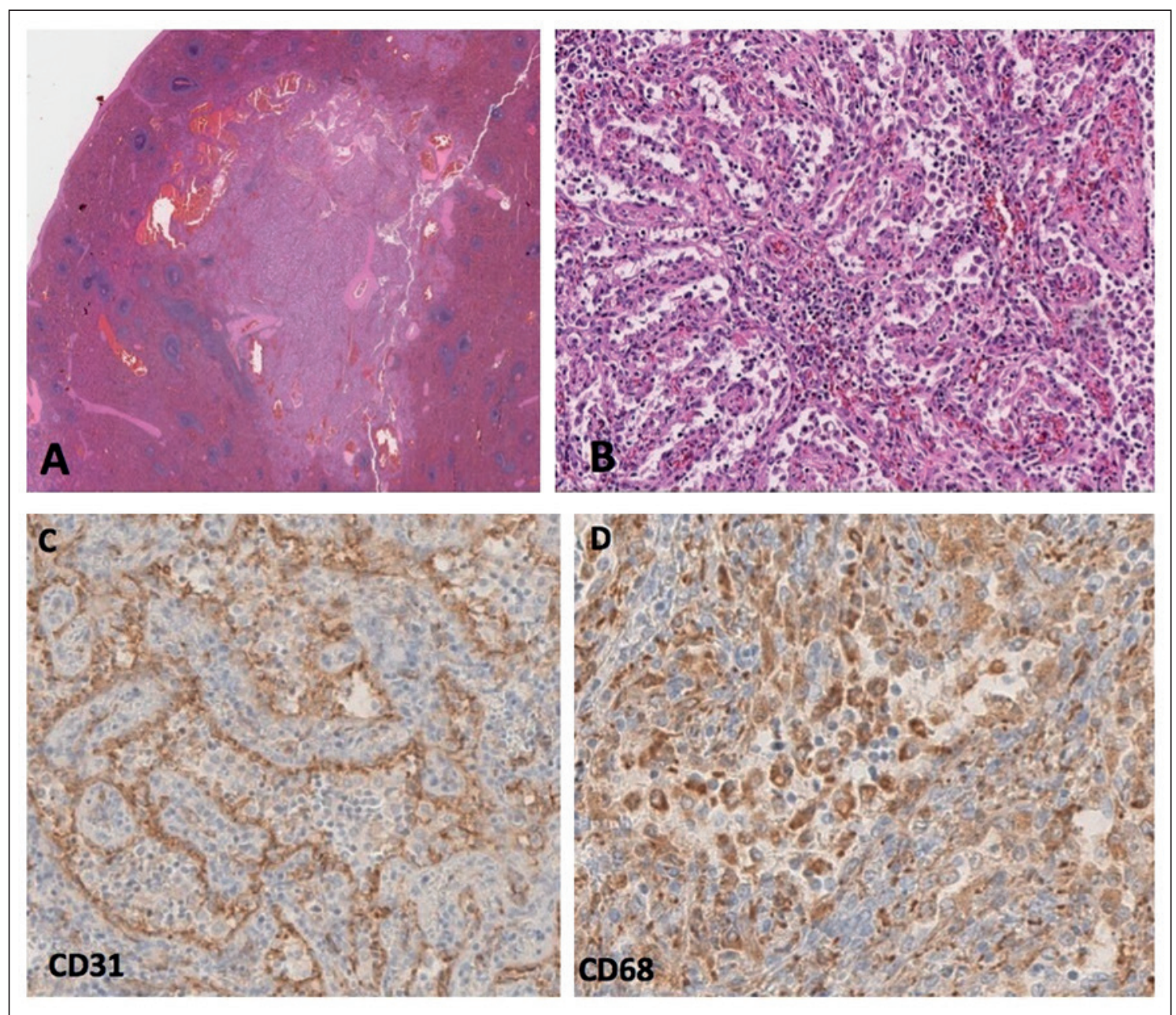

Figura 2. A: Corte histológico de bazo que muestra una lesión vascular bien delimitada en el parénquima esplénico (Aumento 2X). B: A mayor aumento, se observan canales vasculares, revestidos de células endoteliales cuboidales y macrófagos intraluminales (Aumento, 20X). C-D: Las células endoteliales y macrófagos muestran positividad para CD31 y CD68, respectivamente. (Inmunohistoquímica con contra tinción de hematoxilina, 20X).

presentarse como lesiones únicas o múltiples, con componente tanto sólido como quístico, sin una densidad específica ni un patrón específico de captación de medio de contraste 7 . Otros métodos de imagen no presentan mejor rendimiento en la caracterización de estos tumores esplénicos. Por esto, no es posible realizar el diagnóstico definitivo mediante imágenes, siendo necesario el análisis inmunohistopatológico del bazo ${ }^{8}$. No se recomienda la biopsia por punción debido a su bajo rendimiento y riesgo de sangrado asociado.

El tratamiento y diagnóstico es mediante esplenectomía ${ }^{9}$. Cai el al ${ }^{10}$ plantean que el abor- daje laparoscópico es seguro en estos pacientes, ofreciendo menor tasa de complicaciones postoperatorias, menor tiempo operatorio y menores pérdidas sanguíneas.

En una serie con 25 pacientes, $60 \%$ de ellos presentó en su estudio una lesión neoplásica coexistente $e^{4}$. Originalmente, se planteó una asociación con tumores de tipo adenocarcinoma. Sin embargo, actualmente se reconoce su asociación con neoplasias de tipo epitelial, mesenquimáticas o hematológicas ${ }^{4}$. Por esto, diversos autores plantean la necesidad de un seguimiento estricto y una búsqueda activa de neoplasias concomitantes fren- 
te al diagnóstico de $\mathrm{ACL}^{4}$. De acuerdo a nuestra revisión de la literatura, el caso clínico expuesto corresponde al cuarto caso reportado de asociación entre ACL y adenocarcinoma prostático.

Adicionalmente, en pacientes con ACL es frecuente la presencia de enfermedades autoinmunes como enfermedad de Crohn, colitis ulcerosa, espondiloartritis anquilosante y lupus eritematoso sistémico, entre otros ${ }^{4}$. Esta asociación podría reforzar la idea de que desregulaciones inmunológicas jugarían un rol en la patogénesis de este tipo de tumores.

Histológicamente, el ACL se diferencia del resto de las neoplasias vasculares esplénicas en que sus células poseen diferenciación híbrida endotelial e histiocitaria ${ }^{3,11}$. Al utilizar marcadores endoteliales e histocitarios típicos como CD31, CD34 y CD163, puede ser confundido con otras lesiones vasculares esplénicas como hamartoma y hemangioma ${ }^{12}$. La presencia del marcador vascular WT-1, en conjunto con la ausencia de ERG, se han descrito como hallazgos altamente específicos de $\mathrm{ACL}^{12}$. Asimismo, la claudina-5 y el VEGFR también han sido descritos como marcadores vasculares específicos de este tipo de tumor ${ }^{4}$.

Finalmente, la baja frecuencia de esta enfermedad, sumado a las manifestaciones clínicas y hallazgos tomográficos inespecíficos, conlleva a que establecer un diagnóstico preoperatorio de ACL sea prácticamente imposible. Sin embargo, debe sospecharse como diagnóstico diferencial frente a una lesión focal esplénica, más aun en el contexto de alguna neoplasia primaria conocida. Por el contrario, frente al diagnóstico histológico de ACL, consideramos que debe realizarse una búsqueda activa de una neoplasia concomitante no conocida.

\section{Referencias}

1. Cordesmeyer S, Pützler M, Titze U, Paulus H, Hoffmann MW. Littoral cell angioma of the spleen in a patient with previous pulmonary sarcoidosis: a TNF- $\alpha$ related pathogenesis? World J Surg Oncol. 2011; 9: 106.

2. Thipphavong S, Duigenan S, Schindera ST, Gee MS, Philips S. Nonneoplastic, benign, and malignant splenic diseases: cross-sectional imaging findings and rare disease entities. AJR Am J Roentgenol. 2014; 203 (2): 315-22.

3. Falk S, Stutte HJ, Frizzera G. Littoral cell angioma. A novel splenic vascular lesion demonstrating histiocytic differentiation. Am J Surg Pathol. 1991; 15 (11): 102333.

4. Peckova K, Michal M, Hadravsky L, Suster S, Damjanov I, Miesbauerova $\mathrm{M}$, et al. Littoral cell angioma of the spleen: a study of 25 cases with confirmation of frequent association with visceral malignancies. Histopathology 2016; 69 (5): 762-74.

5. Levy AD, Abbott RM, Abbondanzo SL. Littoral cell angioma of the spleen: CT features with clinicopathologic comparison. Radiology. 2004; 230 (2): 485-90.

6. Venkatanarasimha N, Hall S, Suresh P, Williams MP. Littoral cell angioma in a splenunculus: a case report. Br J Radiol. 2011; 84 (997): e11-3.

7. Zhang YH, Liu LM, Wang WP, Ding H, Wang XN, Xia HS. Littoral cell angioma of the spleen: sonographic-pathologic comparison. J Ultrasound Med. 2013; 32 (4): 691-7.

8. Shah S, Wasnik A, Pandya A, Bude RO. Multimodality imaging findings in image-guided biopsy proven splenic littoral cell angioma: series of three cases. Abdom Imaging. 2011; 36 (6): 735-8.

9. Yano H, Imasato M, Monden T, Okamoto S. Hand-assisted laparoscopic splenectomy for splenic vascular tumors: report of two cases. Surg Laparosc Endosc Percutan Tech. 2003; 13 (4): 286-9.

10. Cai YQ, Wang X, Ran X, Liu XB, Peng B. Laparoscopic splenectomy for splenic littoral cell angioma. World J Gastroenterol. 2015; 21 (21): 6660-4.

11. Arber DA, Strickler JG, Chen YY, Weiss LM. Splenic vascular tumors: a histologic, immunophenotypic, and virologic study. Am J Surg Pathol. 1997; 21 (7): 827-35.

12. O’Malley DP, Kim YS, Weiss LM. Distinctive immunohistochemical staining in littoral cell angioma using ERG and WT-1. Ann Diagn Pathol. 2015; 19 (3): 143-5. 